\title{
US Neutron Facility Development in the Last Half-Century: A Cautionary Tale
}

\author{
John J. Rush*
}

Large multi-user facilities serve many thousands of researchers in fields from particle physics to fundamental biology. The great expense-up to billions of current-day dollarsand the complexity of such facilities required access to extensive engineering and research infrastructures, most often found at national laboratories and the largest research universities. Although the development of such facilities has been largely successful and the research results unique and often spectacular, the processes for choosing, funding, and locating them were complex and not always productive. In this review, I describe the troubled efforts over the past fifty years to develop neutron research facilities in the United States. During this period, the US has moved from a preeminent position in neutron-based science to a lesser status with respect to Europe. Several major US centers of excellence have been shut down and replaced with more focused capabilities. I compare the US efforts in neutron facilities with parallel developments in Europe and Asia, discuss the reasons for this state of affairs, and make some suggestions to help prevent similar consequences in the future.

Key words: neutron research; national laboratories; Department of Energy; National Institute of Standards and Technology; research reactors; spallation neutron sources; Institut Laue-Langevin; National Academy of Sciences.

\section{Introduction}

A major element in the great expansion both of US and international science since the Second World War has been the development of large multi-user facilities to serve many thousands of researchers around the world with applications in almost all fields, ranging from particle physics to fundamental biology. As was the case for the Manhattan Project, the scale of these facilities required a level of planning, infrastructure, and professional and budget resources-up to a billion dollars or more-which in the US can generally only be provided by the federal government and its array of laboratories. A number of US government agencies established

\footnotetext{
* John J. Rush is an adjunct professor in the Materials Science and Engineering Department at the University of Maryland. He was the leader of neutron scattering research at the National Institute of Standards and Technology until 2005, where he was a NIST Senior Fellow.
} 
and supported a growing number of these facilities, most notably the Department of Energy (DOE)-previously the Atomic Energy Commission (AEC)-with ever-increasing costs and commensurate benefits. The resulting scientific and engineering advances were impressive and in many cases spectacular.

The process that led to the creation of special large research facilities and the related competition and evaluation was complex and not always elevating. For the most part, over the years, these efforts have been successful in deciding the major facilities to be developed and their timing and location, albeit often with inadequate operational funding. In this article, I describe the pattern of events and decisions and their consequences that surrounded the development of major neutron research facilities in the US since the 1960s. These intense efforts over more than 40 years yielded decidedly mixed results. Moreover, they demonstrate how a string of sometimes unconnected judgments, actions, and mistakes can impede the progress of any scientific field, large or small, at great cost in funds and professional resources. I hope that my review of these events might be of some use to those engaged in proposing, supporting, and choosing future large research ventures.

Much of this article reflects my own perspective, which I developed during many years in the field of neutron research. I spent my early career at neutron facilities at Brookhaven and Argonne National Laboratories before devoting over three decades in neutron research and leadership at the National Bureau of Standards/National Institute of Standards and Technology (NBS/NIST). I also participated in many of the committees and panels related to neutron research and facilities that are reviewed in this article. I should note that I have limited somewhat the use of names in this brief history, since the focus is primarily on the events, rather than the individuals involved. This is partly due to my preference not to emphasize individual roles and actions, given the great number of people who took part in the events described over several generations of managers and research leaders. Although the problems and issues discussed here might have been addressed differently given a different cast of characters, they were largely systemic.

Finally, my analysis of events has relied on a wide range of reports, papers, and other references, some of which are listed at the end of this article for further investigation by the reader. It also reflects my discussions with dozens of scientists, engineers, and managers who were knowledgeable about the events and decisions I describe.

\section{The 1940s to the 1960s}

Nuclear research reactors in the United States, Canada, Europe, and the Soviet Union grew rapidly in both number and sophistication after the Second World War. It was clear that the unique properties of the neutron offered powerful advantages for nuclear and other fundamental physics studies, for chemical 
analysis by neutron activation, and especially for probing the structure and dynamics of materials and molecules. ${ }^{1}$ The sensitivity of neutron scattering to different isotopes, most notably hydrogen and deuterium, provided a powerful and unique tool to determine the structure of molecular and macromolecular materials, such as polymers. The neutron magnetic moment allows direct probing of the atomic-scale structure and properties of magnetic materials, which underpins modern computer technology; the deep and non-destructive penetration of materials by neutron beams allows unique imaging of materials and products, including modern-day fuel cells; and neutrons have extraordinary potential for the study of atomic and molecular dynamics in all classes of materials over nine orders of magnitude in time, from $10^{-5}$ to $10^{-14}$ seconds. As neutron research grew in the 1940s and 1950s, these properties showed promise for revolutionary advances in broad areas of science and engineering, promise realized in the following decades. In addition, intense modern neutron sources are critical for the production of isotopes used worldwide for medical diagnosis and treatment and for many industrial applications. The supply of these isotopes is currently of major concern in the United States.

By the late 1950s, dozens of reactors dedicated to research, isotope production, nuclear engineering, and other pursuits were being developed all over the world, particularly in North America and Europe, in government laboratories, universities, and even some US industries. To take advantage of neutrons' enormous potential for research on materials, emphasis was placed on achieving higherintensity sources to fully develop neutron scattering applications and to explore new opportunities in nuclear physics and chemistry. Progress prior to $1960 \mathrm{had}$ already led to work by Clifford Shull and Bertram Brockhouse on neutron diffraction and inelastic scattering, which would ultimately result in the 1994 Nobel Prize in Physics. During the 1960s, the US AEC developed a number of major reactor facilities, most notably the 40 megawatt (MW) High Flux Beam Reactor (HFBR, figure 1) at the Brookhaven National Laboratory (BNL)-almost totally dedicated to neutron beam research-and the 100 MW High Flux Isotope Reactor (HFIR) at Oak Ridge National Laboratory (ORNL), whose original purpose was to provide ultra-high neutron fluxes to produce isotopes, as well as to feed four neutron beam tubes. At the same time, the Department of Commerce funded the development of the Neutron Beam Split-Core Reactor (NBSR) at NBS to provide large, intense beams for neutron scattering research, along with other facilities for neutron chemical trace analysis and irradiations. In addition to these facilities, many smaller or special purpose research reactors at or above $1 \mathrm{MW}$ power were designed and constructed. Fairly large reactors were built at the University of Missouri (MURR), the Massachusetts Institute of Technology (MITR), and Iowa State University (Ames Laboratory). Similar growth of research reactor development occurred in Canada, Europe, and the rest of the developed world. The International Atomic Energy Agency provides a list 


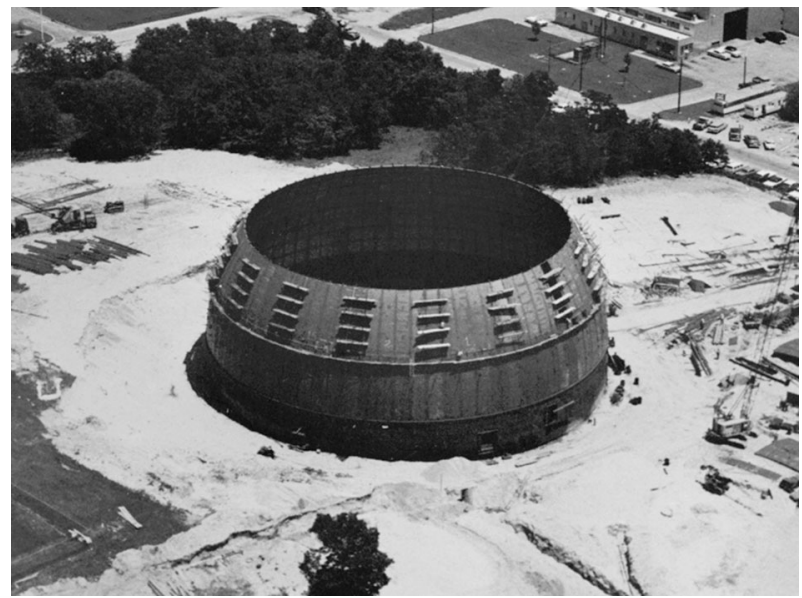

Fig. 1. Brookhaven's High Flux Beam Reactor (HFBR) containment vessel under construction, June 1962. Credit: Department of Energy, Brookhaven National Laboratory.

of over 600 research reactors developed starting in the 1940s, including over 250 in North America. ${ }^{2}$

\section{Late 1960s: On the Brink of a Golden Age with the US in the Lead}

By the late 1960s, the United States was in a very strong position, largely due to the major advances in neutron scattering research on materials at the HFBR and the HFIR and later at the NBSR (figure 2). Research reactors in Britain, France, Germany, and Holland were also making great strides, but the American flagships were performing the highest-impact research, particularly in solid state physics and chemistry. Bragg reflection from large single crystals was traditionally used to select particular energies from the "white" neutron beams produced by neutron sources, but these monochromators were not very efficient. The discovery of highly efficient pyrolytic graphite (which is only ordered in one dimension) allowed fabrication of monochromators that provided much higher neutron intensities and had a great impact in research on new materials by allowing the use of much smaller single crystals as samples. To add to this rosy outlook, Argonne National Laboratory (ANL) was beginning construction of the Argonne Advanced Research Reactor $\left(\mathrm{A}^{2} \mathrm{R}^{2}\right)$, a $100 \mathrm{MW}$ facility that promised a several times gain over the HFBR and the HFIR in neutron fluxes (up to $2 \times 10^{15}$ neutrons/ square centimeter per second) in the variety of beams that would emanate from the reactor's beryllium neutron reflector. These developments pointed toward a golden era for American neutron science, but there was trouble and international competition on the way. 


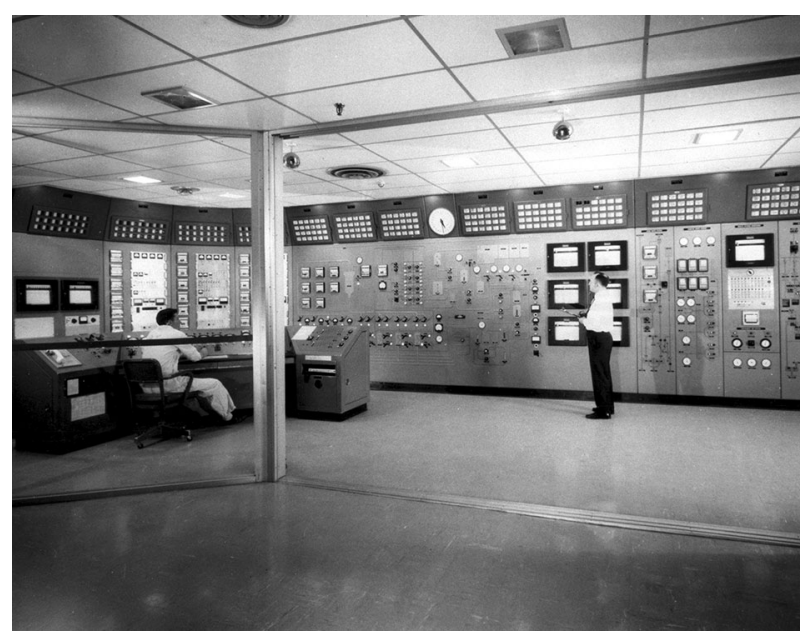

Fig. 2. Operations of the High Flux Isotope Reactor at the AEC's Oak Ridge National Laboratory are monitored from its instrument-packed control room, ca. 1968. Credit: Department of Energy.

\section{$\mathbf{A}^{2} \mathbf{R}^{\mathbf{2}}$ and the Institut Laue-Langevin}

In the mid-1960s, two of the major research reactors being designed and developed were the $57 \mathrm{MW}$ reactor at the Institut Laue-Langevin (ILL) in Grenoble, France, and the $100 \mathrm{MW} \mathrm{A} \mathrm{R}^{2}$ at Argonne. These facilities had very different origins. The ILL was a major project jointly funded and developed by France and West Germany as a result of the agreement in 1964 between German Chancellor Konrad Adenauer and French President Charles de Gaulle that the two countries should come closer through joint technical and diplomatic enterprises. The $\mathrm{A}^{2} \mathrm{R}^{2}$ was a less dramatic gesture by the US AEC to allow Argonne National Laboratory to take the next step in US research reactor technology. At a cost of $\$ 25$ million, the $\mathrm{A}^{2} \mathrm{R}^{2}$ was in a way a consolation prize for ANL's loss of a larger, more ambitious $200 \mathrm{MW}$ reactor dubbed "Mighty Mouse," which was rejected by the AEC in the late 1950 s along with its $\$ 70$ million price tag.

The ILL received ample support, including funding for a large experimental hall and a suite of unique instruments with a series of "guide" tubes to transport neutron beams from a large deuterium cold-neutron source located in the high neutron flux region of the reactor. Innovations implemented in the ILL were the fruit of earlier research at reactors in West Germany, France, and Britain. On the other hand, the $\mathrm{A}^{2} \mathrm{R}^{2}$ was cancelled by the AEC in 1968 a few months after a lackluster groundbreaking ceremony, partly due to conflicts with the AEC Reactor Division but mainly because of the lack of enthusiasm and adequate planning and support by ANL management and research staff. This was perhaps the first cancellation of a large basic research facility already under construction at a US 
National Laboratory. The consequences for the neutron research field in the United States would become obvious in the years to come, but at that time few people outside of ANL paid much attention.

\section{The 1970s: Opportunities and Conflicts}

As the 1970s began, the great impact of solid state research using neutron spectrometry to study fundamental vibrational and magnetic excitations in solids, as well as (to some extent) chemical crystallography and nuclear physics at the HFBR and the HFIR, still buttressed the US position in neutron science. Brookhaven in particular was attracting a widening range of collaborators from industrial labs (such as AT\&T's Bell Laboratories or IBM) and major universities to explore critical dynamical and structural properties of new materials, which were often key to developing new products and technologies. In addition, several instruments at the NBS reactor and at the lower power reactors at Argonne and Ames Laboratory were also producing important results. A young cadre of scientists led by Jack Carpenter at Argonne, recovering from the $\mathrm{A}^{2} \mathrm{R}^{2}$ debacle, actively explored the use of high energy proton beams to produce pulsed highintensity neutron beams by nuclear spallation reactions as a new approach for neutron beam research. Japanese researchers were taking the same approach to advance neutron source technology.

In 1972, the ILL in Europe achieved full power and (after some early snafus) began producing results with cold (very low energy) neutrons, particularly using small-angle neutron scattering and high-resolution spectroscopy, which represented a great leap forward in neutron research that could not be matched in the US. Totally new information emerged on the nanoscale structure of polymers, macromolecular fluids, and many other materials critical to the development of industrial products. Funds to further exploit the advantage of the superior design of the ILL reactor were on the way.

\section{A Hinge of Fate}

In 1976, the National Academy of Sciences assembled a committee (of which the author was a member) to examine neutron research and related neutron source issues. This major study was stimulated by the Energy Research and Development Administration (ERDA), soon to be renamed the Department of Energy, and involved many of the leading US figures in neutron science at the time, along with independent experts in materials research. A main driver was ERDA's desire to examine the potential of the new large pulsed neutron source being proposed for development by Argonne National Laboratory. ${ }^{3}$ It had been more than a decade since the development of the major AEC neutron sources at Brookhaven and Oak Ridge and the feeling, at least at ERDA headquarters, was that it was time for a new source. 
The panel deliberations were intense and extensive. In the end, the case for full support and more instrumentation for the "flagship" HFBR and HFIR reactors was judged to be stronger than the case for rapid development of a high-power pulsed neutron source, and the recommendations reflected this. ${ }^{4}$ The Argonne pulsed-source proposal was praised, but put on a phased track for development. The NBS reactor was judged an excellent but lower-priority center, as were the largest university reactors. These judgments were possibly influenced by the presentation by Los Alamos National Laboratory (LANL) of a prospective highintensity pulsed neutron source using an existing $800 \mathrm{MeV}$ proton acceleratorthe Los Alamos Meson Physics Factory-which would have lower costs because of LANL's ancillary use of nuclear defense facilities and funds. Certainly, the results of this panel were in part a reflection of the sometimes intense competition among the DOE National Laboratories, which could dominate judgments on new opportunities.

In any event, eight years after the $\mathrm{A}^{2} \mathrm{R}^{2}$ cancelation Argonne lost its bid to fund the world's first high-power spallation neutron source, much to the chagrin of Don Stevens, director of the ERDA Materials Division. In the meantime, progress in Europe, most notably the explosion of new accomplishments at ILL and the decision by the British to join the ILL and to proceed with the development of a major new pulsed neutron source akin to the proposed Argonne facility, showed a clear turn of the tide in the international arena. These developments were discussed in the 1977 NAS report, but not extensively.

In the next few years, neutron research and facility funding by the DOE was relatively flat. There were attempts to reverse the decision to phase in slowly the Argonne Intense Pulsed Neutron Source (IPNS), but these were rejected. For example, John Deutch from MIT, then director of the Office of Science at the DOE, told a delegation of US researchers and DOE managers, notably Don Stevens and Sam Werner from the University of Missouri-the chair of the IPNS Project Advisory Committee-that there would be no increase in funding for IPNS and that he did not want to discuss it further. There were some interesting developments at other sources, however; Brookhaven and NBS managed to get funding to increase reactor power, which would occur by the mid-1980s-increasing the HFBR from 40 to $60 \mathrm{MW}$ and the NBSR from 10 to $20 \mathrm{MW}$. After a close competition between the HFBR, the HFIR, and the NBSR, the NSF funded the HFIR for a small-angle neutron scattering (SANS) facility, and NBS provided separate funds to develop a SANS at the NBSR. But for the most part, with the major DOE laboratories competing for the limited resources for neutron research and because the DOE authorities were not overly concerned, things remained in a flat, somewhat self-satisfied mode.

This state of affairs led the DOE to appoint an ad-hoc panel in 1980, chaired by William Brinkman from Bell Laboratories, to examine the current neutron situation under the assumption that little additional funding would be available for new projects or facilities. The Brinkman panel decided in the end that they had 
little choice but to recommend improvements at the HFBR and the HFIR to keep the US competitive. While praising the efforts at Argonne, the panel recommended that, unless new funds were available, the IPNS at Argonne should be phased out and that the Los Alamos plan to expand their Weapons Neutron Research facility into a world-class neutron source be favored in order to allow pulsed-source development. This approach was taken partly because the Los Alamos leadership, along with the nuclear weapons support arm of the DOE, indicated clearly that funding would be provided largely outside the civilian research budget of the DOE. As a bizarre ending to these lean neutron years, the DOE Office of Science-wisely, as it turned out-called off the termination of IPNS to preserve the status quo, with little new funding. An excellent article appeared in Science magazine in early 1981, "Will US Skip Neutron Scattering Derby?" summarizing the report, its potential consequences, and the ambivalent attitude of the DOE. ${ }^{5}$

In the early 1980s, therefore, neutron research in the US was at a virtual standstill, whereas European neutron research received several times the US level of support. Inadequate attention was given to the fact that the greatest successes being achieved at the ILL were due to cold neutrons as well as the fundamentally different design of its reactor. The HFBR and the HFIR were indeed competitive in innate neutron intensity and superior in certain key research areas, such as triple-axis spectrometry, yet they were inferior in basic design and could not compete in versatility or in the cold-neutron arena. The HFBR had installed a hydrogen cold source, but it was of small area, could only provide neutrons to several instruments, and was far less flexible than the large cold sources at ILL. By then, it was clear that the availability of intense beams of cold neutrons opened up new vistas in neutron scattering research, particularly for the study of macromolecular and other large structures in materials and for probing slower motions in materials and molecules. Compounding the difficulty of this situation was the emerging success of early developments and research with synchrotron x-rays, spearheaded by work at Cornell and Stanford Universities, which drove a strong call for new funding to exploit clear opportunities for even greater advances.

\section{The 1980s: Opportunity Knocks Again}

In 1981, the inauguration of the Reagan administration led to new emphasis on science in the US, particularly basic science, even though the economy was suffering great inflation, with the attendant economic and budgetary pressures. George (Jay) Keyworth from Los Alamos National Laboratory was confirmed as the President's Science Advisor and proceeded to carry out the Reagan basic science (and Strategic Defense Initiative) program (figure 3). During the early 1980s, many federal labs and universities proposed new science initiatives, including a number of new large facilities for research on materials. As was the usual practice, these expensive proposals led to the creation of panels and committees to 


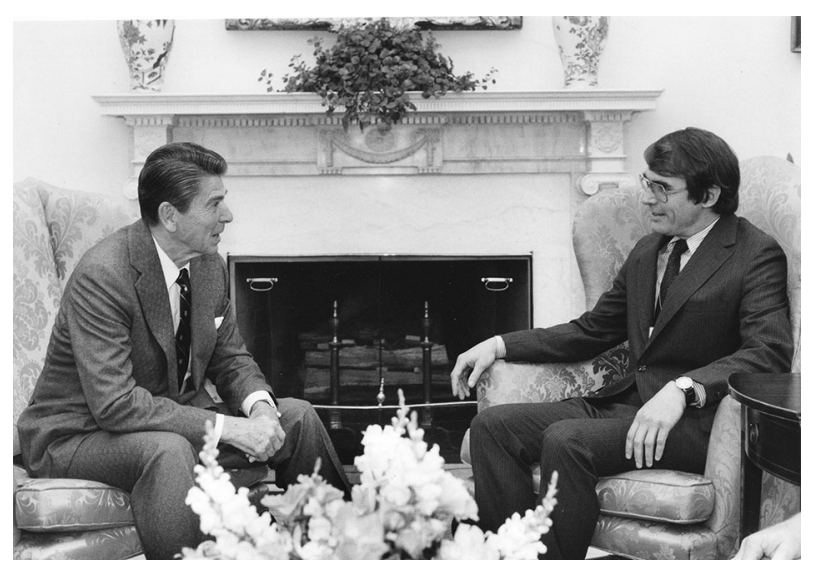

Fig. 3. George (Jay) Keyworth meets with President Reagan, July 1981. Credit: White House Photograph, courtesy AIP Emilio Segrè Visual Archives.

examine and compare their merits, while also surveying the scientific opportunities involved. Thus, for example, panels were organized by the Solid State Sciences Committee of the National Research Council to examine the status of both synchrotron radiation research (1982) and neutron research (1983) in the United States. The Synchrotron Study reviewed the status of synchrotron radiation sources as the National Synchrotron Light Source (NSLS) at Brookhaven was starting operations, and the neutron study covered both neutron research and proposals for new capabilities, along with comparisons with foreign neutron sources. Many other workshops, ad-hoc committees, and panels generated a plethora of proposals for new or expanded materials research facilities. The DOE laboratories were in full competitive mode.

\section{The Seitz-Eastman Committee}

This state of affairs led Keyworth, late in 1983, to appoint a committee cochaired by Frederick Seitz, former president of the NAS, and Dean Eastman (IBM) to review the many proposals that were being generated and then make recommendations on US needs and priorities. ${ }^{6}$ The Seitz-Eastman Committee was to be one of the most important and influential scientific committees of the last part of the twentieth century. Its membership and consultants included many of the most prominent scientists and administrators of that era. These included H. Guyford Stever (former Presidential Science Advisor and NSF Director), Walter Kohn (UCSB), William Slichter (AT\&T Bell Laboratories), Mildred Dresselhaus (MIT), and Michael Fisher (Cornell). The fields and facilities the committee surveyed included neutrons, synchrotron radiation, high magnetic fields, and several other large laser, electron, muon, and computational research centers. 
The Seitz-Eastman Committee represented a golden opportunity for the neutron community, which had now gone over twenty years without initiating a new source, to move the field forward. In the intense competition that followed, proposals for new or improved facilities were presented to the committee from all of the major DOE national laboratories as well as Stanford, Cornell, MIT, and the National Bureau of Standards, involving a total long-range cost of about $\$ 5$ billion. The neutron facility proposals came from Argonne, Brookhaven, Oak Ridge, Los Alamos, and NBS. In a close vote, a new $6 \mathrm{GeV}$ x-ray synchrotron source was chosen by the committee to receive top priority, followed by a next-generation research reactor.

The Committee's specific recommendations for the construction of new major facilities were, in the following order:

1. A 6-GeV Synchrotron Radiation Facility...designed to make optimum use of the new scientific and technological opportunities presented by insertion devices... [to improve the brightness of the x-ray beams by orders of magnitude].

2. An Advanced Steady State Neutron Facility...to achieve about ten times the flux of existing machines [worldwide]....

3. A 1 to $2 \mathrm{GeV}$ Synchrotron Radiation Facility...centered around insertion devices but optimized for the vacuum ultraviolet and soft X-ray region...for research in chemical physics, electron spectroscopy, and imaging techniques....

4. A High-Intensity Pulsed Neutron Facility...future improvements in neutron sources...will probably come from alternative approaches the most promising of which is based on pulsed neutron sources...[but] future action...should be based upon results with lower intensity pulsed sources. ${ }^{7}$

Because the ultimate development costs of the first two priorities were each in the $\$ 1$ billion range, the committee recommended staging their funding, with the neutron source starting two years later. These results were to have a significant negative impact on the neutron field. The Advanced Reactor project was to be delayed and the US posture in pulsed neutron source development was set back considerably.

On the brighter side, the Seitz-Eastman Committee recognized the great scientific impact of cold neutrons over the past decade in Europe, particularly at the ILL. For new capabilities at existing neutron sources, they gave top priority to the establishment of the first American centers for cold-neutron research at NBS's Neutron Beam Split-core Reactor and Brookhaven's High Flux Beam Reactor. The HFBR already had a cold-neutron source installed and the NBSR had received FY 1985 funding for a cold source to be installed in the very large thimble designed into the split-core region of its $\mathrm{D}_{2} \mathrm{O}$ (heavy water) moderator. 
The trends of the next few years looked promising. In particular, the NBS reactor doubled its power to $20 \mathrm{MW}$ in 1985 and installed a large $\mathrm{D}_{2} \mathrm{O}$ ice-based cold-neutron source in 1987, which greatly improved intensities available to its 8-meter SANS machine. NBS also achieved development and construction funding over a six year period for the first cold-neutron research facility in the United States, with seven large neutron guide tubes and fifteen instruments, in line with the Seitz-Eastman Committee's priorities. The DOE provided a smaller increase in funds to expand instrumentation at the Los Alamos pulsed-neutron source. Nevertheless, Brookhaven's plan to build a guide hall, including both cold and thermal neutron guide tubes and a dozen instruments, was not funded by the DOE, and the Argonne next generation pulsed-neutron source was shelved indefinitely.

\section{The Trivelpiece Plan and Trouble at the DOE Reactors}

One of the central factors guiding the development and siting of large research facilities in the United States after the mid-1980s was a plan largely devised by Alvin Trivelpiece in coordination with the major DOE Laboratories. ${ }^{8}$ Trivelpiece, later director of Oak Ridge, was the director of the DOE Office of Science from 1981-7 during the Reagan Administration. ${ }^{9}$ This plan essentially distributed the large facilities that the Seitz-Eastman Committee had recommended for DOE funding (as well as other large-scale projects) among the DOE national laboratories and several other sites. This approach, which was commensurate with the culture of the DOE in balancing capabilities at the national labs, had a considerable impact on US neutron research and development. For example, the highest Seitz-Eastman priority for totally new facilities, the $6 \mathrm{GeV}$ Synchrotron Source, was sited in 1985 at Argonne National Laboratory and called the Advanced Photon Source (APS), which in turn made it unlikely that a new pulsed-neutron source or major improvements to the IPNS could be funded for the foreseeable future. In the same period, the European community decided to construct the next generation European Synchrotron Radiation Facility (ESRF) next to the ILL in Grenoble. The DOE did not support the Brookhaven HFBR guide hall proposal, possibly because BNL was being favorably considered for a major accelerator project, the Relativistic Heavy Ion Collider (RHIC). Another part of the Trivelpiece Plan was the designation of Oak Ridge as host for the new $300 \mathrm{MW}$ research reactor, the Advanced Neutron Source (ANS). The DOE's favored site for the 1-2 GeV Synchrotron Source (third in the Seitz-Eastman rankings) was Lawrence Berkeley Laboratory (LBL) in California. This distribution of new facilities left two of the top neutron research centers in the US with considerably weakened prospects. But the worst was still to come.

By 1987, the construction of the APS at Argonne had begun, Oak Ridge was in the early phases of the design of the ANS, and NBS was initiating the design and construction of its Cold Neutron Research Facility, greatly aided by the Seitz- 
Eastman recommendation. But things started to go awry for the main DOE reactors. First, in early 1987 engineers at the High Flux Isotope Reactor discovered potential evidence of embrittlement in the reactor pressure vessel, which could have significantly diminished its lifetime. This coincided with a general concern that arose at that time about the safety of the DOE nuclear and weapons-related facilities. The HFIR was shut down for three years, until 1990. It was finally discerned that the originally perceived problems were largely due to inadequately interpreted mechanical test results. The HFIR was restarted at $85 \mathrm{MW}$ and was still running in 2015. When Admiral James D. Watkins became the secretary of energy in 1989 under George H. W. Bush, he instituted "tiger teams" to visit the various DOE Laboratories and facilities to assure that safety systems were adequate. In this climate of elevated concerns, the engineering staff at the HFBR became uncertain in 1989 about the validity of the safety analysis involving loss of coolant flow in the reactor-again unwarranted as it turned out-and the reactor was shut down for two years, returning online in 1991, but only at half power (30 MW).

\section{The Advanced Neutron Source}

Though the late 1980s were a time of troubles at the HFIR and the HFBR, the construction of the cold-neutron facility at NBS and the planning for the $300 \mathrm{MW}$ Advanced Neutron Source (ANS) were proceeding with a high degree of optimism. There was no move to provide construction funding for the ANS, but Oak Ridge management and the DOE provided encouragement and some funds to allow design and planning to proceed. A National Steering Committee for the ANS was organized, chaired by the present author. When Trivelpiece became the ORNL Director in 1989, he placed the highest priority on the new reactor and approved a management structure with Colin West, a nuclear engineer, as ANS project director and John Hayter, who had joined ORNL from the ILL in Grenoble earlier in 1980s, as the scientific director.

After several years of active preliminary design, the DOE called together a panel under Walter Kohn from the University of California, Santa Barbara, to analyze the status of neutron science and to review the relative merits of the research reactors and pulsed spallation neutron sources being proposed. In 1993, the Kohn Panel confirmed the judgment of the Seitz-Eastman Committee and recommended sequential funding of the ANS followed by a megawatt-class pulsed neutron source. ${ }^{10}$ Troubling signs appeared in the early 1990s, however, because the cost estimate of the ANS had climbed considerably above earlier predictions, driven in part by the decision to build the reactor and its radiation containment according to power reactor standards. The perceived necessity to serve special needs for irradiation facilities, isotope production, and nuclear science also increased the cost. In addition, the management structure for ANS development, which emphasized engineering criteria, led to conflicts within the Oak Ridge team. 
There remained as well strong feelings among some members of the neutron community that a large spallation source was a better option.

Early in the Clinton Administration, scientific and political support for the ANS was steady, but by late 1994, as the cost projections for the project approached $\$ 3$ billion, the DOE Office of Science and the White House Office of Management and Budget removed its funding from the president's FY 1996 budget. The ANS was cancelled in early 1995, only three months after Shull and Brockhouse received the Nobel Prize for the development of neutron scattering at reactors at Oak Ridge and Chalk River, Canada (figure 4). Thus, another attempt to bring the US back into an international leadership position in neutron science had failed amid concerns in Congress and the administration about expanding costs and possible management problems, as well as concerns about the ANS use of highly enriched uranium.

\section{The Spallation Neutron Source}

The failure of the ANS project constituted another major blow to the neutron field. It led to a great deal of soul-searching at the DOE and prompted the DOE Basic Energy Sciences (BES) program to create new committees and panels to examine remaining opportunities for a new neutron source and improvements at existing facilities. The early nineties also saw the formation of the Neutron Scattering Society of America, representing a large fraction of US and Canadian neutron researchers, but this organization was not engaged as a general advisory body for neutron facility development. The obvious next step was to follow the second recommendation of the Kohn Report and develop a next generation spallation source, while attempting to keep the cost within the DOE \$1 billion guidelines. Proposed improvements at the HFBR, the HFIR, and the Los Alamos Neutron Scattering Center (LANSCE) facilities also received community support. The NIST Cold Neutron Research Facility was already operational with a new large hydrogen cold-neutron source, achieving great success and a rapid increase in the number of research users. ${ }^{11}$

There was a competition among Argonne, Brookhaven, Los Alamos, and Oak Ridge regarding the siting of a new pulsed neutron source, but the DOE designated the last of these, whose turn it was for a large facility, as the preferred site. There was a flurry of support for Argonne, which with IPNS had carried the spallation neutron banner for twenty years, but Oak Ridge's design bid was accepted in 1997.

The road ahead for the Spallation Neutron Source (SNS) was not without problems. Given the scope of the project, with a cost estimate of $\$ 1.4$ billion, and the fact that Oak Ridge was not one of the DOE Laboratories with a strong mission in accelerator development, a plan was developed to parcel out development of major components among five laboratories (ANL, BNL, LBL, LANL, and ORNL) under a memorandum of agreement. Difficulties arose in achieving a 

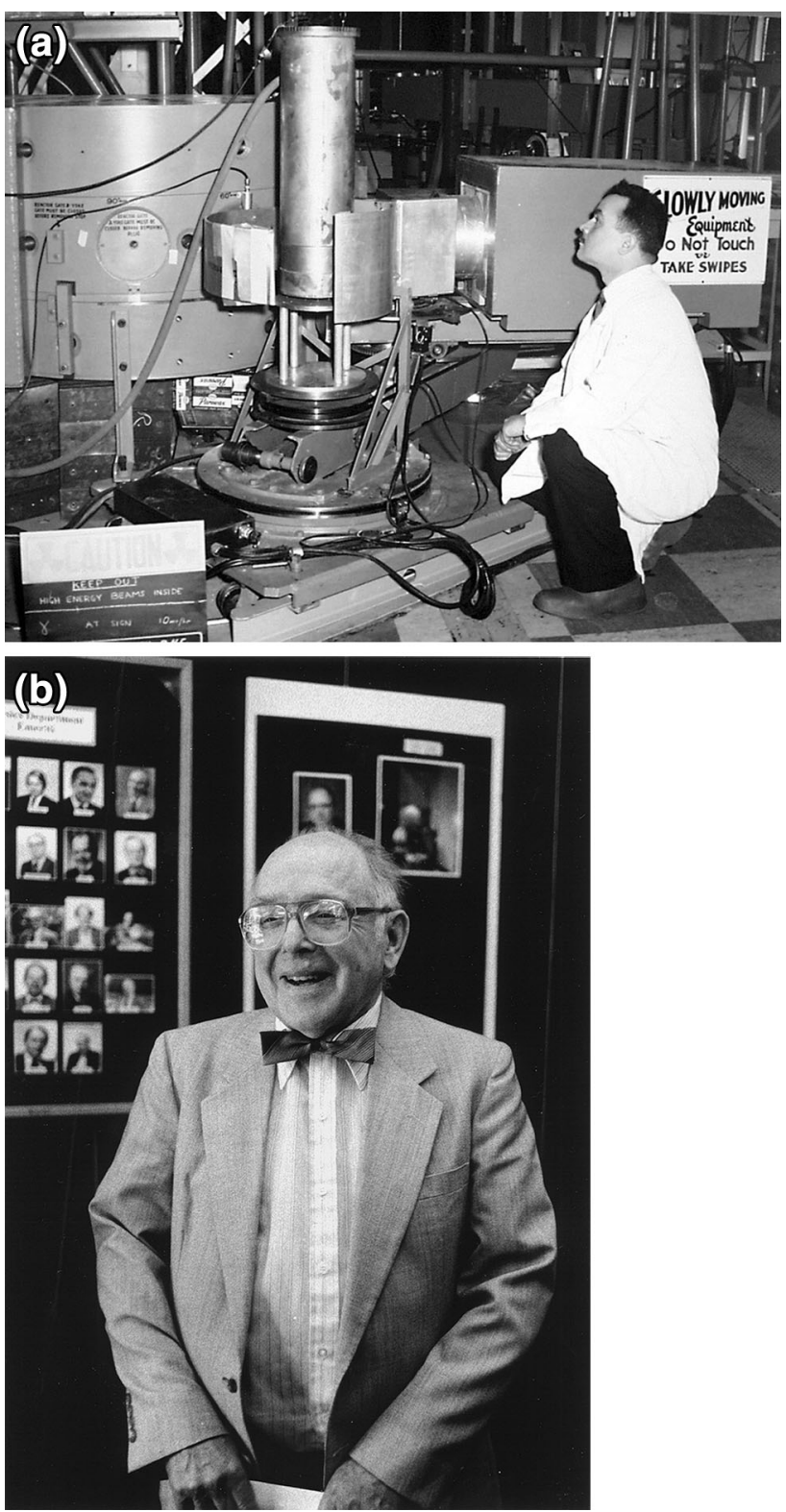

Fig. 4. The laureates of the 1994 Nobel Prize in Physics: (a) Bertram Brockhouse, with a tripleaxis spectrometer manufactured by Atomic Energy of Canada Limited; (b) Clifford G. Shull. Credits: Atomic Energy of Canada Limited, Chalk River, Ontario, reproduced under the Creative Commons License (https://creativecommons.org/licenses/by-nc-nd/2.0/legalcode); US Department of Energy. 
satisfactory arrangement between the laboratories and in staffing key ORNL positions on the project, and, of all things, a controversy over taxes to be collected by the State of Tennessee. Congress nevertheless appropriated $\$ 39$ million between FY 1996 and FY 1998 for conceptual design and \$130 million in 1999 to start detailed design and construction activities. But in 1999, the Congress, particularly the House of Representatives, expressed serious concerns about the progress of the SNS and criticized the DOE and ORNL for perceived management problems. ${ }^{12}$ There was even a threat to cancel the project.

In 1999, Oak Ridge and BES responded to Congressional and community concerns by appointing a new associate laboratory director for the SNS, David Moncton, who had extensive experience with both synchrotron and neutron sources, notably his successful development and leadership of the Advanced Photon Source (APS) at Argonne National Laboratory. Under Moncton's leadership, the project was substantially modified, including the choice of a superconducting linear accelerator provided by a new partner, the Jefferson Laboratory in Virginia. The SNS accelerator and target station was put on the road to completion, successfully meeting the bulk of its goals at an ultimate cost, including instrumentation, of close to $\$ 2$ billion. At that time, it was one of the most expensive civilian construction projects in DOE history. At the same time, the High Flux Isotope Reactor was funded for instrumentation upgrades, including a cold source in one beam hole to provide cold neutrons to four or five instruments in a new guide hall.

Other DOE neutron facilities were not as fortunate. The HFBR at Brookhaven experienced a leak in its spent fuel storage pool in 1997, which resulted in tritium seeping into the groundwater. The reactor, which happened to be shut down at the time of the discovery, was not allowed to reopen. Over the next two years, organized Long Island community and external protests helped to create political pressures that led to an order by Energy Secretary Richardson in 1999 to permanently close the HFBR, the DOE's best neutron source. ${ }^{13}$ Partly as a consequence of these events, the long-time contractor for operating BNL, Associated Universities, Inc., was fired and replaced after a competition, along with the upper BNL management. ${ }^{14}$

In 2007, DOE-BES also terminated the operation of IPNS at Argonne, the first internationally prominent pulsed neutron source. LANSCE achieved a measure of success at the turn of the millennium, establishing reliable operation of the source and a number of valuable instruments. This followed many years of difficulties, some associated with the dual nature of the role and support structure of this facility, which was divided between civilian and nuclear defense research. At this writing, in spite of recent successes, LANSCE remains on tenuous ground, in part due to the need for a major refurbishment of the $800 \mathrm{MeV}$ accelerator which provides the protons on the neutron target. In fact, the president's 2015 budget terminates DOE Office of Science funding for this facility.

During this period of troubles and complex decisions at the DOE neutron centers, the NBS Reactor, now the NIST Center for Neutron Research (NCNR) 
became the nation's most productive and internationally competitive neutron source, with more research users than any other US neutron center. This was largely due to the successful development of a cold-neutron guide hall with fifteen instruments that were mostly unique in the US. The NCNR benefited from having a very large cold-neutron source and large, low-background neutron beams, as well as a less complex management structure.

The SNS at Oak Ridge achieved first protons on target in 2006 and reached its full proton energy of $1.4 \mathrm{MW}$ several years after that. Thus, after forty years the United States had a totally new neutron source that was the world's highest-power spallation source. Some elements of the chaos of preceding decades remained, nonetheless. David Moncton, whose leadership was key to the success of the SNS project, left ORNL in 2001 due to a disagreement with the DOE about funding for SNS commissioning and is currently the director of the MIT Nuclear Reactor Laboratory. In addition, the SNS, now the most expensive civilian DOE user facility aside from Fermilab, costing about $\$ 190$ million a year in FY 2014, experienced some growing pains bringing its suite of neutron scattering instruments to completion. In late 2011, with a push from the DOE Office of Science, there was a major reorganization of SNS management and staff. At this writing, progress in the instrumentation and science efforts remains steady, as it does for the improved facilities at the High Flux Isotope Reactor. There are longer-range plans to increase the power of the SNS above $2 \mathrm{MW}$ and to design and build a second target station with instruments geared toward colder neutrons. Whether the Department of Energy will support three neutron facilities at Oak Ridge remains to be seen.

In sum, the overall US neutron picture in the last few years has improved somewhat. The SNS and the HFIR have achieved significant success, while the NCNR has been relicensed and is about to open a second cold-neutron guide hall with next-generation instrumentation. The Los Alamos Lujan Center is facing an uncertain future. The president's budget for FY 2015 would effectively eliminate critical BES support for this facility. Since the 1960s, other materials probes, such as synchrotron x-rays, nuclear magnetic resonance, and laser spectroscopy, have greatly expanded their ability to study key structures and properties of materials and molecules, including biomolecules, at the atomic and nanoscale level. Neutron sources, however, have also expanded their scope, particularly using cold-neutron facilities, and continue to provide unique and essential information on all classes of materials and macromolecules. In spite of the difficulties outlined here, research at American neutron sources has led to dozens of national science and engineering awards.

\section{The Consequences of the Last Five Decades}

The past five decades in the development of neutron sources and research in the United States have yielded decidedly mixed results. There were major advances in neutron-based science and instrumentation. But a half-century that began with a 
clear international lead and optimistic prospects ended with a diminished US position. Brookhaven and Argonne National Laboratories, two of the mainstays of American neutron science, are no longer in the game, except for relatively small groups of first-rate neutron scattering researchers. Oak Ridge is and will remain for some time the only major force in DOE-supported neutron sources, with the world's most powerful spallation neutron source (along with the HFIR) and an annual neutron operations and science budget that is over $80 \%$ of the US total. The NCNR at NIST will continue to provide an internationally competitive center with expanding capabilities in cold-neutron research.

It is clear that the leadership position in neutron research has moved to Europe, starting with the ascendency of the Institut Laue-Langevin in the 1970s, but including a number of advanced neutron sources in the last three decades: the ISIS Spallation Source in Great Britain and the Orphée Reactor in France in the 1980s; the Swiss Spallation Source (SNQ) in the 1990s; and the FRM II reactor in Munich in 2000 , to name only a few. ${ }^{15}$ In all, there are six world-class neutron centers in Europe, even as a number of others have been shut down. The Scandinavian countries, with help from the wider European community, are designing a next generation long-pulse spallation source of $5 \mathrm{MW}$ power, to be completed in southern Sweden in the 2020s. ${ }^{16}$ In the meantime, Japan has in recent years brought on line a new spallation source which rivals the SNS in power and capability. China has commissioned a new high-flux research reactor and is designing a spallation source. Other countries including Australia have developed new and improved research reactors. A list of some major neutron sources worldwide in place in 2014 is provided in Table 1.

\section{Factors in the US Neutron Slide: Are Changes in Approach Possible?}

What are the factors that complicated the advance of US neutron facilities for forty years? Can some steps be taken to prevent similar events in the future? Some of the problems involved technical errors and weakness in management at the DOE laboratories, which helped to accelerate the demise of the $A^{2} R^{2}$ reactor at Argonne and the HFBR at Brookhaven, bring about the loss of the ANS, and make the path of the SNS at Oak Ridge onerous. Other difficulties were due to the increasing costs of constructing and operating facilities-though the scientific payoff increased even more-and the tightening of budgets in the late 1970s as proposals for new large facilities increased, such as the rise and great success of synchrotron radiation sources. Some measure of responsibility for decades of uncertainty in the neutron field must be assigned to the DOE Office of Science and its BES program (and earlier to the AEC), to the culture of competition among the labs, and to micromanagement and mixed signals from the technical bureaucracy.

The original debacle of the Argonne Advanced Research Reactor, cancelled by the AEC after the groundbreaking, appeared to be due to the lack of clear 


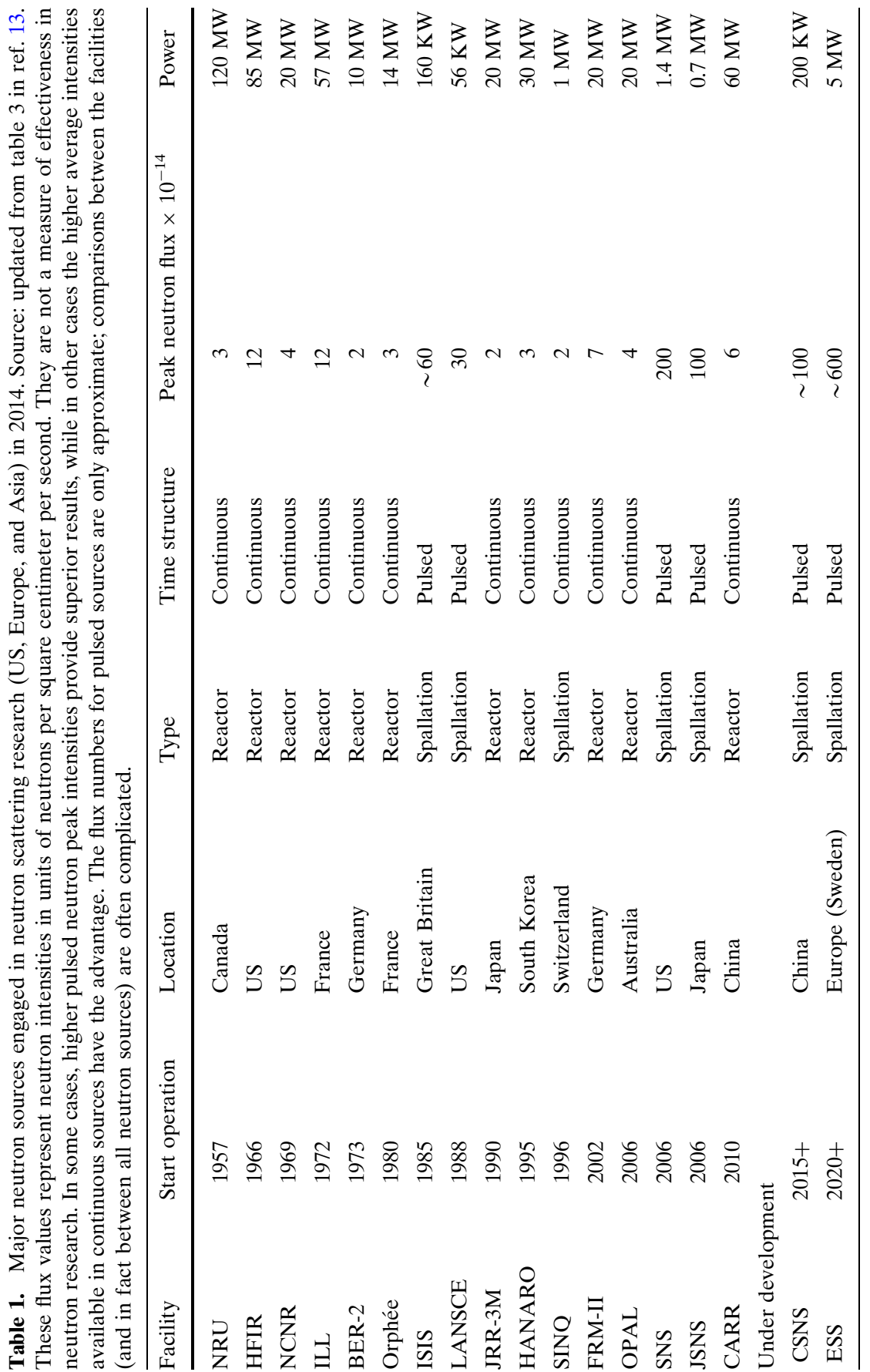


planning and enthusiasm by Argonne leadership at a time when the lab management was in an uncertain state. Reactor design problems and conflicts with the AEC nuclear reactor program were also a factor. The AEC was perhaps influenced by the decision in the 1960s to site Fermilab in Illinois. There appears to be no clear or coherent explanation, but the outcome was deleterious for Argonne and for the neutron field.

The set of events that prevented Argonne from developing the world's best pulsed neutron source in the early 1980s included changing signals from the DOE, three NAS and DOE panels that did not give first priority to the Argonne proposal, a desire to upgrade the best DOE reactors, and a period of relatively flat funding for neutron research. The enticing prospect of developing an advanced spallation source at Los Alamos using an existing $800 \mathrm{MW}$ proton accelerator, thus in principle at less expense, was also a contributing factor, though the defense mission and location of LANL ultimately limited the success of this option.

The chance to build the ANS in the 1990s, which would have greatly exceeded the performance of the ILL, was lost due in part to lack of strong science-driven management at Oak Ridge and the decision to build the reactor to power-reactor standards, but not focusing sufficiently on neutron scattering as the priority. Perhaps the ANS National Steering Committee, which I chaired, should have pushed harder for measures to reduce cost. The resulting price tag of $\$ 3$ billion was just too high, so another opportunity was lost. Of course, it did not help that safety concerns at the existing Brookhaven and Oak Ridge reactors (thought they turned out to be largely not credible) arose in the same period.

Finally, the successful funding and construction of the SNS at Oak Ridge was almost done in by less-than-successful management before David Moncton, a leader with strong skills and experience in overseeing development of the Advanced Photon Source at Argonne, came to the rescue.

It should at this point be noted that the neutron field was not the only largefacility area that suffered serious setbacks and delays during the decades in question. The cancelling of the Superconducting Super Collider in Texas in 1993 and the ISABELLE proton collider at BNL in 1983 were two other notable examples. ${ }^{17}$ The great expansion in large-facility opportunities and costs in recent decades meant that not all worthy proposals could be funded in any field. In the end, however, it was not only the lack of funding that reduced our national neutron research posture. Delays and inadequate use of the funds made available were at least as important.

It is difficult to change the way the DOE and its national laboratories function. Both technical needs and politics drive the DOE to try to strike a balance between the various laboratories. This is nowhere more apparent than in the siting of major national facilities. This approach, along with fiscal constraints and management failures, resulted in major delays in the AEC/DOE neutron program between 1966 and 2006, along with the loss or waste of hundreds of millions of dollars in facility operations and development. Such failures occurred in spite of-and in fact partly 
because of - a plethora of studies, workshops, high-level committees, and other interactions among the national labs and with DOE headquarters.

The neutronic events of the last half century suggest that major facility development in the civilian sector and the related balancing act and competition between the DOE laboratories should be driven more directly by the judgments of the appropriate scientific communities, and that the greatest weight be given by the DOE to those labs with the best experience, skilled personnel, and infrastructure to develop the project and community support, rather than "whose turn it is." This is especially true in the development of very large, expensive national user facilities such as accelerators and research reactors. In addition, for facilities that serve thousands of users, location, ease of transportation access, and scientific environment should be key factors, as has largely been the case in the development of US synchrotron radiation facilities. Such a general approach will not only serve American science and technology best, but will also encourage the best use of the national resources that are available to fund these facilities. This will be especially true in the coming years, which will likely see fewer but larger facilities serving even more research users.

Finally, the history of facility development and success shows that other government entities are at times highly successful in supporting or hosting such large facilities, provided the project is in line with the agency's mission. Clear examples are the NCNR and the Center for Nanoscale Science and Technology (CNST) at NIST, funded by the Department of Commerce, and the National High Magnetic Field Laboratory at Florida State University, the Cornell High Energy Synchrotron Source (CHESS), and nanocenters at various universities and laboratories, all supported by the National Science Foundation.

\section{Acknowledgements}

I would like to thank Laura Williamson for her efforts in preparing this historical review and Mike Rowe and Ron Cappelletti for their insightful comments on the content.

Open Access This article is distributed under the terms of the Creative Commons Attribution 4.0 International License (http://creativecommons.org/licenses/by/4.0/), which permits unrestricted use, distribution, and reproduction in any medium, provided you give appropriate credit to the original author(s) and the source, provide a link to the Creative Commons license, and indicate if changes were made.

\section{References}

${ }^{1}$ A recent paper on early neutron diffraction clearly reflects the exciting development phase in the 1940s: T. E. Mason, T. J. Gawne, S. E. Nagler, M. B. Nestora, and J. M. Carpenter, "The Early Development of Neutron Diffraction: Science in the Wings of the Manhattan Project," Acta Crystallographica A 69 (2013), 37-44. 
${ }^{2}$ Research Reactor Database, International Atomic Energy Agency, http://nucleus.iaea.org/ $\mathrm{RRDB} / \mathrm{RR} /$ ReactorSearch.aspx? $\mathrm{rf}=1$.

${ }^{3}$ Catherine Westfall, "Surviving to Tell the Tale: Argonne's Intense Pulsed Neutron Source from an Ecosystem Perspective," Historical Studies in the Natural Sciences 40 (2010), 350-398.

${ }^{4}$ National Research Council, "Neutron Research on Condensed Matter: A Study of Facilities and Scientific Opportunities in the United States" (Washington, DC: National Academy of Sciences, 1977).

${ }^{5}$ Arthur Robinson, “Will U.S. Skip Neutron Scattering Derby?,” Science 211 (1981), 259-263, on 263.

${ }^{6}$ National Research Council, "Major Facilities for Materials Research and Related Disciplines," (Washington, D.C.: National Academy Press, 1984).

${ }^{7}$ Ibid., 4-5.

${ }^{8}$ Westfall, "Surviving to Tell the Tale" (ref. 3).

${ }^{9}$ Alvin Trivelpiece, "Some Observations on DOE's Role in Megascience," History of Physics Newsletter 9 (Fall 2005), 14-15, http://www.aps.org/units/fhp/newsletters/upload/spring05.pdf.

10 "Neutron Sources for America's Future: Report of the Basic Energy Sciences Panel on Neutron Sources," DOE/ER-076P (January 1993), http://science.energy.gov/ /media/bes/besac/pdf/ Neutron_source_america_future.pdf.

${ }^{11}$ J. J. Rush and R. L. Cappelletti, "The NIST Center for Neutron Research: Over 40 Years Serving NIST/NBS and the Nation," NIST Special Publication 1120 (August 2011), http://www. nist.gov/customcf/get_pdf.cfm?pub_id=908047.

${ }^{12}$ Kai-Henrik Barth, "The Department of Energy's Spallation Neutron Source Project: Description and Issues," Congressional Research Service Report R.L. 30385 (December 1999).

${ }^{13}$ For a detailed discussion of the HFBR situation, see Robert P. Crease, "Anxious History: The High Flux Beam Reactor and Brookhaven National Laboratory," Historical Studies in the Physical and Biological Sciences 32 (2001), 41-56.

${ }^{14}$ Government Accountability Office, "Department of Energy: Information on the Tritium Leak and Contractor Dismissal at the Brookhaven National Laboratory," Report GAO/RCED-98-26 (November 1997), http://www.gao.gov/products/RCED-98-26.

${ }^{15}$ See, e.g., "Report on the Status and Needs of Major Neutron Scattering Facilities and Instruments in the United States," Office of Science and Technology Policy (June 2002), 16-17, http:// www.whitehouse.gov/files/documents/ostp/Issues/NeutronIWGReport.pdf.

16 “European Spallation Source (ESS) Conceptual Design Report," ESS-2012-001 (February 2012), http://esss.se/documents/CDR_final_120206.pdf. Many other details about the source and its scientific goals can be seen at http://europeanspallationsource.se/.

${ }^{17}$ One of these major accelerator setbacks has been carefully reviewed in Robert P. Crease, "Quenched! The ISABELLE Saga, II," Physics in Perspective 7 (2005), 404-452.

Materials Science and Engineering Department University of Maryland

College Park, MD 20742-2115, USA

e-mail: j.rowe@nist.gov; john.rush@nist.gov 